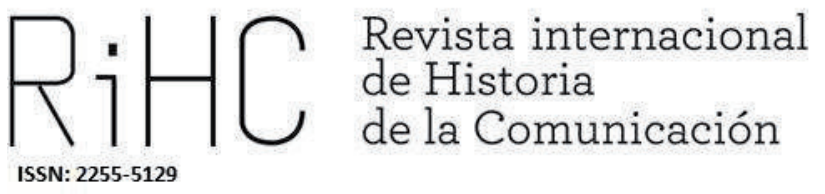

\title{
LA INFORMACIÓN TAURINA EN LA PRENSA BARCELONESA (1850-2010)
}

Bullfighting information in the Barcelona Press (18502010)

DOI: http://dx.doi.org/10.12795/RiCH.2021.i16.16

Recibido: 9-4-2021

Aceptado: 25-5-2021

Publicado: 30-6-2021

Josep Guixà Cerdà

Periodista

josep_guixa@hotmail.com

ORCID (I) 0000-0002-8974-2494

GUIXÀ, Josep (2021): “La información taurina en la prensa barcelonesa (1850-2010)",en Revista Internacional de Historia de la 
Resumen: La gran implantación de los espectáculos taurinos en Barcelona, donde llegaron a existir simultáneamente tres plazas de toros, obligó a la prensa local a posicionarse sobre la llamada "fiesta nacional". Por lo general, los diarios en castellano publicaban regularmente crónicas taurinas, aunque también hubo excepciones como la de "La Vanguardia" entre los años 1900 y 1939. Por su parte la prensa en catalán, adscrita al catalanismo político, se abstuvo de informar sobre los festejos que se celebraban en Barcelona, salvo para criticar la tauromaquia, aspecto en el que destacó algún semanario satírico. A pesar de la simbiosis existente entre el antitaurinismo y el nacionalismo catalán, el autor concluye que la línea editorial de la prensa ante las corridas de toros obedecía a cuestiones identitarias.

Palabras clave: Toros, prensa, catalanismo, antitaurinismo, Barcelona, La Vanguardia.

Abstract: The great implantation of bullfighting spectacles in Barcelona, where there were even three bullrings at the same time, forced the local press to take a position on the so-called "national festival". In general, Spanish-language newspapers regularly published bullfighting chronicles, although there were also exceptions such as "La Vanguardia" between 1900 and 1939. On the other hand, the Catalan press, ascribed to political Catalanism, abstained from reporting on the celebrations that took place in Barcelona, except to criticize bullfighting, an aspect in which some satirical weeklies stood out. In spite of the existing symbiosis between anti-bullfighting and Catalan nationalism, the author concludes that the editorial line of the press regarding bullfights obeyed to identity issues.

Keywords: bullfights, press, catalanism, anti-bullfighting, Barcelona, La Vanguardia.

\section{Introducción}

En los últimos tiempos el ascendiente de los críticos taurinos sobre aficionados y profesionales ha declinado y el papel de la crónica taurina como fuente de lenguaje coloquial o radiografía del contexto social o político son reminiscencias del pasado. La influencia creciente de los medios audiovisuales, los portales de internet y las redes sociales como creadores de estados de opinión o prescriptores del gusto de los aficionados, han convertido a los críticos en figuras anacrónicas o marginales dentro de la profesión periodística. En el mejor de los casos, han tenido que reconvertirse en profesionales todoterreno (Zabala de la Serna, Antonio Lorca) o renunciar a su condición de cronistas para reseñar sucintamente las corridas en la línea de los revisteros de antaño (Andrés Amorós). Esto no impide que el historiador taurino o el aficionado interesado en épocas remotas del toreo, sigan volviendo una y otra vez a las crónicas de "Don Modesto", Gregorio Corrochano, Cañabate o "Clarito".

Por alguna razón, salvando a Néstor Luján, bien conocido por su extensa y variopinta obra literaria, los críticos taurinos barceloneses no han despertado el interés de los aficionados nostálgicos ni recibido los honores de la posteridad libresca. Del mismo 
modo, así como en la historiografía reciente autores como Jaume Sobrequés o Josep M. Solé i Sabaté han encontrado en el Futbol Club Barcelona claves para entender la Cataluña contemporánea, los historiadores catalanes han rehusado adentrarse en la fiesta taurina con idéntico objetivo.

El presente trabajo dibuja las líneas maestras de la posición de la prensa barcelonesa ante el espectáculo taurino, permitiendo entender cómo éste ha sido excluido del relato oficial de la Cataluña contemporánea. Esta omisión, lejos de ser un fenómeno reciente, relacionado con las campañas antitaurinas de comienzos del siglo XXI, hunde sus raíces en el pasado. Un periodo que para nosotros se inicia en 1850 ya que, previamente, la inauguración de la plaza El Torín en 1834 y la clausura de la misma un año después a raíz de unos graves incidentes, revistieron un carácter de excepcionalidad que impidieron el desarrollo de unas rutinas periodísticas que mostrasen la posición editorial de los medios. Por otra parte, la brevedad de las temporadas en El Torín (por citar un caso, en 1876 el primer festejo se celebró el día de San Juan) dificultaban la consolidación del periodismo taurino local. El anonimato y la discontinuidad de las reseñas son una constante en la segunda mitad del siglo XIX su aparición al día siguiente de la corrida dependía de variables como la disponibilidad de los periodistas o el espacio con que contaba el periódico-, todo lo cual dificultaba el seguimiento de la actualidad taurina. Esto explica que las monografías publicadas ya en el siglo XX por Ventura Bagüés, considerado la principal autoridad en aquella época, sean en realidad misceláneas de anécdotas o semblanzas, desprovistas de una visión de conjunto o de cuadros estadísticos.

Con todo, el género de la crónica taurina se encamina hacia una normalización cuyo punto de inflexión es el abono de la temporada de 1888 (dieciséis festejos, siete de ellos entre abril y mayo), más o menos coincidente con la Exposición Universal celebrada entre abril y diciembre de aquel año. Con el cambio de siglo el espectáculo taurino se profesionaliza a la vez que su tratamiento periodístico adquiere regularidad y brillantez. De la figura del revistero que se limita a enumerar los detalles técnicos de la lidia, se evoluciona hacia el cronista que describe momentos destacados de la corrida con subjetividad y pretensiones literarias. En puridad el periodismo taurino barcelonés empieza a comienzos del siglo $\mathrm{XX}$, y se extiende hasta la fecha fatídica de 2010 en que la abolición de las corridas en Cataluña supuso también la abolición de la información taurina en las cabeceras barcelonesas. Nuestro retrato de familia de un oficio extinguido no incluye el periodismo oral, pese a la influencia que alcanzaron en su día las transmisiones radiofónicas de Gerardo Esteban y Soler Serrano, las críticas radiadas de Julio Gallego Alonso o Antonio Santainés, y las conferencias o charlas en los clubes y peñas taurinas (un subgénero en sí mismo). Debido a que la mayoría de estas manifestaciones periodísticas tuvieran lugar en una época sin libertad de prensa, en que la atención a la "Fiesta Nacional" formaba parte del discurso cultural dominante, su interés como apuesta editorial nos ha parecido menos relevante. Sin 
embargo, siguiendo con el ámbito audiovisual, no debería subestimarse el grado de penetración de los reportajes taurinos del noticiero cinematográfico NODO entre un público en principio indiferente a los toros.

\section{Metodología y fuentes}

En contra de lo que es habitual en un trabajo de investigación académica, hemos optado por el discurso narrativo como una forma idónea de mostrar la evolución de la moderna fiesta de los toros y cómo ésta interacciona con el periodismo taurino. El artículo se ha estructurado en apartados que, de forma sencilla, permitan distinguir entre diferentes tipos de medios escritos, cada uno con su propia actitud ante el hecho taurino. La principal línea divisoria tiene que ver con el idioma empleado. Así, el examen de la prensa generalista en catalán nos hizo constatar la ausencia de información taurina en sus páginas (salvo un breve periodo durante la transición democrática), lo que nos indujo a consultar bibliografía de intelectuales catalanistas que mostraron explícitamente su oposición a las corridas

En cuanto a la numerosa prensa en castellano, para orientarnos en un territorio de vastas proporciones, en el que ser sistemático resulta poco menos que imposible, procedimos a localizar los escasos directorios o listados existentes sobre periodismo taurino barcelonés. Si bien todos ellos incorporan interesantes juicios de valor, decidimos desestimarlos una vez pudimos sopesar dichas valoraciones. Cuando un autor de la categoría de Rafael López Chacón afirma que Enrique García Cerralbo "Carrasclás" "figura a la cabeza de los escritores taurinos con que ha contado siempre Barcelona" (López Chacón, 1946: 35), conviene no olvidar que López Chacón escribía bajo el franquismo en un diario del Movimiento y que "Carrasclás" era el padre del conocido dirigente falangista Enrique García Ramal. Asimismo, cuando Ricardo Huertas López recoge la afirmación de Ventura Bagüés de que la mayoría de revistas taurinas respondían a "un "periodismo de "capillitas" y cuyo único objetivo era el de forzar a los toreros a unas publicidades que mantuvieran las revistas" (Huertas, 1974: 82), no resulta ocioso saber que Bagüés era acusado por alguna de estas publicaciones de extorsionar a los toreros a cambio de obtener anuncios para su periódico ${ }^{1}$. Por lo demás, las enumeraciones de periodistas no aspiran a la exhaustividad, pero la de Pizarroso Quintero tiene la virtud de reivindicar el papel de los fotógrafos en el periodismo taurino (Pizarroso, 1994: 311-313). Por otra parte, en nuestros rastreos hemerográficos nos fueron de gran ayuda las colecciones digitales de los semanarios barceloneses “La Fiesta Nacional” (1904-1908) y “La Fiesta Brava” (1926-1936), puesto

\footnotetext{
1 “Oro y Plata". 16 y 23 de mayo de 1931.
} 
que los resúmenes de prensa y las polémicas entre críticos formaban parte de sus contenidos habituales.

Ante la imposibilidad de elaborar censos completos, decidimos seleccionar algunas cabeceras para su consulta. En nuestras catas atendimos no tanto a variables cuantitativas (espacio, tratamiento tipográfico, regularidad en la publicación, etc.) cuanto a elementos informativos que revelaban la influencia entre los aficionados, la independencia crítica o la voluntad de estilo. Así, el hecho de firmar con iniciales (una práctica habitual de los redactores de periódicos para desmarcarse del contenido de una información) podía denotar una menor implicación personal que la de un crítico que firmaba con su nombre completo o cuya identidad era bien conocida detrás de un pseudónimo peculiar. La influencia social del medio era también una variable a considerar para la selección, y, en este sentido, descubrimos que las dos cabeceras más vendidas en la Barcelona de entreguerras (La Vanguardia y El Diluvio) eran también las más sintomáticas de las contradicciones existentes entre la posición ideológica de un medio y la función de servicio informativo que conlleva el periodismo.

\section{Una aproximación a la visión de la fiesta taurina en la prensa barcelonesa (1850- 2010)}

\subsection{Los toros en la prensa barcelonesa en la segunda mitad del siglo XIX}

Un año después de la inauguración del Torín (1834), la primera plaza de toros estable de Barcelona, una mansa corrida de Zalduendo provocó la ira de los aficionados. Suele afirmarse que aquella corrida del día de San Jaime de 1835 fue el detonante de la famosa quema de conventos, pero la protesta de los aficionados se mezcló con la de otro tipo de manifestantes. Sin embargo, en la mentalidad de las autoridades el viejo hilo que conectaba tauromaquia y desórdenes públicos se vio fortalecido, y el Torín fue clausurado durante quince años. Al reabrir sin incidentes, en 1850, el comentarista "V.B." (el escritor y futuro diputado Víctor Balaguer) se congratuló en su crónica del Diario de Barcelona: "Nos cabe la más cumplida satisfacción de poder dar fin a nuestras revistas de toros con hacer observar ese laudable, aunque debido 
comportamiento del pueblo catalán"2. En contraste, su compañero de periódico, el notable publicista Joan Mañé y Flaquer, no pensaba que las corridas fuesen extrapolables a Barcelona. En 1853 argumentó que, para gozar de ellas, "necesito verlas en armonía con cuanto las rodea, (...). Por esta razón me repugnan en Cataluña y me agradan en Andalucía las corridas de toros, expresión de la gracia, agilidad y desenvoltura propias de aquel país" (Mañé, 1856: 221).

La relación con la tauromaquia del precursor del federalismo, Valentí Almirall, también parece haber sido ambivalente. Pla escribe que Almirall y su amigo Josep Balari, un reputado helenista, fueron "uns terribles entusiastes de les curses de braus" (Pla, 1973: 16), pero en 1873 el ideólogo federalista pidió su supresión en las Cortes de la Primera República. Curiosamente, como presidente de la Casa de Caridad, propietaria de los terrenos donde se asentaba el coso taurino, tuvo que dar su aprobación a la temporada de abono del Torín. En 1879 Almirall criticó en sus crónicas madrileñas la inauguración de un nuevo coliseo taurino en la capital ${ }^{3}$, anticipando cuál sería la posición de la prensa catalanista sobre el toreo. La idea recurrente entre los intelectuales de la "Renaixença" de que la tauromaquia no armonizaba con los valores y costumbres catalanes, se refleja en que apenas existen reseñas taurinas en catalán en el siglo XIX. En 1879 el semanario satírico L'Esquella de la Torratxa publicó una serie de crónicas firmadas por "Andaluz del Clot" (el escritor republicano Rossend Arús) ${ }^{4}$, pero el autor no dudaba en subrayar las diferencias culturales entre el público y el espectáculo que estaban presenciando. Sobre unos jóvenes socios del Círculo Ecuestre que tomaban parte en una becerrada benéfica, el revistero sentenciaba: "Los senyorets van divertirse fent l'andalús. (...) Com que a mi també m'agrada fer l'andalús, jo'ls donaria una "corrida" [Los señoritos se divirtieron haciendo el andaluz. (...) Como a mí también me gusta hacer el andaluz, yo les daría una "corrida"] 5 .

En las corridas de toros, por su carácter plebiscitario, los aficionados podían cuestionar sin peligro el principio de autoridad de los gobernantes. Al ser presididas por un concejal o por el mismo gobernador civil, el público podía abroncarlos con el pretexto de que no habían devuelto un toro defectuoso al corral o no habían concedido una oreja solicitada clamorosamente por el público. Este espíritu contestatario tuvo un correlato en las reseñas que Rossend Arús publicó en medios como el semanario Pepehillo, que él mismo fundó en 1874 con otro personaje de la masonería, Artur Trilla. Históricamente en Barcelona existieron numerosas publicaciones taurinas, pero

\footnotetext{
${ }^{2}$ V.B. (3 de julio de 1850). "Toros. Tercera media corrida extraordinaria celebrada en la tarde del lunes 10". Diario de Barcelona.

3 'L'Amich de cada festa (28 de septiembre de 1879). “Madrit 1873-1879". Diari Català. Recogido en Almirall, 1984: 41.

${ }^{4}$ Andaluz del Clot (26 de junio de 1879). "Toros". L'Esquella de la Torratxa.

${ }^{5}$ Sin firma (5 de junio de 1879). "Una novillada". L'Esquella de la Torratxa.
} 
ninguna de ellas aparece mencionada en el compendio de la prensa catalana por excelencia, el de Torrent y Tasis, con excepción del semanario Pepe-Hillo, y por el simple hecho de que en el mismo apareció algún poema de Arús en catalán (Torrent, 1966: I, 332). Arús, anticipándose un siglo a un Vázquez Montalbán cuando escribía sobre fútbol con segundas intenciones, aprovechaba sus crónicas taurinas para establecer un paralelismo entre la incompetencia taurina de los ediles y su incompetencia como gobernantes. Las crónicas también le servían para denunciar la adaptación de muchos republicanos a la Restauración, razón por la cual en Pepe-hillo firmaba con el "nom de plumme" de "Juan Mañá y Forner", una alusión burlona al publicista converso Mañé y Flaquer.

El público que predominaba en los tendidos de El Torín era, hasta entonces, de raigambre popular. En el contexto de la Restauración, una de las causas de la fuerte implantación de las corridas en Barcelona fue que los aficionados encontraron una vía de escape subversiva en la rivalidad entre "Frascuelo" y "Lagartijo". Así como el primero era identificado con posiciones monárquicas, el público barcelonés tomó partido por un "Lagartijo" que gastaba fama de republicano. Asimismo, como ya señalamos anteriormente, la Exposición Universal de 1888 vino acompañada de un salto de calidad en los carteles del Torín, a la vez que su entorno del barrio de la Barceloneta era reformado. Un año antes, el gobernador civil Luis Antúnez promulgó el primer reglamento taurino barcelonés, con concesiones al público más refinado, como la retirada inmediata de los caballos de picar muertos en el ruedo (Mhartin, 1902: 31). El periodista Agustí Calvet "Gaziel", a quien su padre llevaba algunos domingos a los toros en un landó con chófer, describe una realidad que aparecía muy desdibujada en la prensa catalanista:

Els catalans, en 1894, i especialment els barcelonins, eren patriotes, com tots els altres espanyols, i els agradaven les mateixes coses: l'eloqüència parlamentària, la "zarzuela" gran, el "género chico" i els matadors de toros (...). El "Colegio Balmes", freqüentat per minyons menestrals i burgesos de la vila de Gràcia i de l'Eixample de Barcelona, estava dominat, quan jo vaig entrar-hi, per dues grans passions: la tauromàquia i la guerra d'Àfrica. (Gaziel, 1981: 64-65)

El éxito entre la burguesía, un año después, de la corrida organizada por el Círculo Ecuestre a beneficio de los familiares de la tripulación del "Reina regente", un crucero de la armada que había naufragado en aguas del Estrecho, confirmó que la moda taurina alcanzaba a las clases adineradas. Acaso como reacción, a finales de aquel 1895 se estrenó la comedia teatral "Toreros d'hivern" (una expresión que alude a los toreros

\footnotetext{
${ }^{6}$ Los catalanes, en 1894, y especialmente los barceloneses, eran patriotas, como todos los otros españoles, y les gustaban las mismas cosas: la elocuencia parlamentaria, la "zarzuela" grande, el "género chico" y los matadores de toros (...). El "Colegio Balmes", frecuentado por muchachos menestrales y burgueses de la villa de Gracia y del Ensanche de Barcelona, estaba dominado, cuando yo entré, por dos grandes pasiones: la tauromaquia y la guerra dé África.
} 
sin contratos o que viven alejados del ambiente taurino), del periodista Anton Ferrer y Codina, que satirizaba la adscripción de los catalanes a la "fiesta". La misma tesis que inspiraría la comedia "Un torero d'hivern", publicada cuatro años después por el comediógrafo Ramon Muntané. A la necesidad del catalanismo de construir un imaginario cultural desprovisto de vestigios españolistas, se añadió poco después un cierto descrédito de la tauromaquia por su movilización durante la guerra de Cuba; durante una corrida en El Torín, la marcha real sonó hasta cuatro veces (Rierola, 1955: 163). Los anatemas con regusto antiflamenquista proliferaron entre los ideólogos catalanistas. Prat de la Riba alertó de que el influjo castellano producía una "bifurcació de la nostra ànima", una "monstruosa coexistència de les dues cultures" (Prat de la Riba, 1999: 13) y el influyente periodista Miquel dels Sants Oliver, pese a dirigir un periódico (Diario de Barcelona) que informaba regularmente sobre el espectáculo taurino, sentenció que el pueblo que "lo ponga como símbolo y quinta esencia de su personalidad, no está muy lejos de declarar que renuncia colectivamente al mundo mental o que para él se considera inhábil, teniendo que acogerse a las regiones subalternas de la vida meramente emocional, instintiva y semisalvaje" (Oliver, 1906: 19-20).

Con el cambio de siglo se había iniciado una fase de expansión comercial del toreo, que tuvo su gran hito en 1900 con la inauguración de la plaza de toros Las Arenas. Si bien el nuevo edificio formaba parte de un proyecto de expansión urbanística, La Veu de Catalunya, órgano de la Lliga Regionalista, despachó la noticia en pocas líneas: "Al cap i al fí, una part del poble assistint a un espectacle exòtic que no arrelarà més de lo que ha arrelat al costat de les carreres del hipódromo i de les batalles de galls"7.

\subsection{Los toros en la prensa barcelonesa del siglo XX}

\subsubsection{Periódicos de información general}

Al comenzar aquella nueva etapa del toreo en Barcelona, en contraste con el silencio unánime de los diarios en catalán (el antitaurinismo de la prensa satírica ya hemos visto que adoptaba otras formas), entre los diarios en castellano sí hubo algunas discrepancias. Predominó la opción de informar regularmente sobre las corridas, pero hubo notorias excepciones como la de La Vanguardia, que suprimió las reseñas taurinas después de casi dos décadas publicándolas. Castelló Ribera, que ha estudiado con detenimiento los primeros años de La Vanguardia, señala que la rúbrica taurina adquirió regularidad y uniformismo con ocasión de la Exposición Universal de 1888

\footnotetext{
${ }^{7}$ [Al fin y al cabo, una parte del pueblo asistiendo a un espectáculo exótico que no arraigará más de lo que ha arraigado al lado de las carreras del hipódromo y de las batallas de gallos]. Sin firma (30 de junio de 1900). "Noticias de Barcelona". La Veu de Catalunya (ed. noche); en la misma edición, otras críticas a la inauguración de Las Arenas de "Pol” (Ferran Agulló) y de Joseph Crusat y Planas.
} 
(Castelló, 2016: 355). Sin embargo, en 1900 la inauguración de Las Arenas fue saludada en portada por el colaborador republicano J. Roca i Roca en estos términos: "iCuanto mejor no estaría en el emplazamiento de este nuevo templo consagrado a la barbarie, un gran Instituto de Artes y Oficios dedicado a la enseñanza de nuestros buenos artesanos...!"8.

La explicación sobre el veto a las corridas que circulaba por el mismo diario en el periodo de entreguerras, y que "Gaziel" recoge en su conocida monografía, es que fue la consecuencia natural de la proliferación en sus páginas nobles de colaboradores europeístas y modernistas contrarios a los toros (Gaziel, 1971: 69-70), pero es dudoso que fuesen ellos quienes marcasen la línea editorial en materia tan sensible. En una monografía muy posterior, Huertas Claveria anota el rumor de que todo obedecía a un capricho personal de Antonia Lallana, la madre bilbaína del primer conde de Godó (Huertas, 2006: 33). Una versión tampoco demasiado creíble, pero que conecta con las semblanzas literarias de Pla o del mismo "Gaziel" que presentan a Ramón Godó Lallana como un personaje extravagante, enganchado a las faldas maternas y por tanto susceptible de querer complacer a su madre. Ramón Godó heredó la propiedad del diario en 1897 y la corrida de las fiestas de la Merced fue reseñada por última vez en $1899^{9}$.

Hay aún otras versiones, ignoradas por los estudiosos del periódico, que circulaban por los ambientes taurinos. Un revistero alicantino establecido en Barcelona desde finales del ochocientos, Tomás Orts Ramos (conocido por el pseudónimo de "Uno al sesgo"), explica en un libro de 1926, al citar de pasada a La Vanguardia, que era un "periódico antitaurino desde que hace muchos años se encargó de su dirección don Modesto Sánchez Ortiz, que salió de El Correo, de Madrid, dirigido entonces por el taurófobo Maestro Ferreras" (léase José Ferreras Toro) (Orts, 1926: 31-32). No era tampoco una versión del todo fiable, pues Sánchez Ortiz asumió la dirección de La Vanguardia en 1888 y, como ya se ha dicho, justamente ese año la información taurina del rotativo se vio reforzada; el veto a las corridas no empezó hasta 1900.

Al abandonar Sánchez Ortiz el diario en 1901, La Vanguardia no sólo continuó sin publicar reseñas de las corridas, sino que dio amplia cobertura a las actividades del movimiento abolicionista. Ello provocó la reacción del semanario barcelonés La Fiesta Nacional, que se confeccionaba en la imprenta de Ramón Molina Opisso y era dirigido por los hermanos Llorens Domènech, uno de ellos casado con la escritora Regina Opisso; por tanto, era una revista que tenía lazos familiares con Alfredo Opisso (el padre de Regina), codirector de La Vanguardia. No hace falta decir que La Fiesta

\footnotetext{
8 J. Roca y Roca (1 de julio de 1900). "La semana en Barcelona". La Vanguardia.

${ }^{9}$ Sin firma (26 de septiembre de 1899). "Toros". La Vanguardia.
} 
Nacional responsabilizaba del veto al otro codirector, Ezequiel Boixet. Al menos era esto lo que se afirmaba en 1904 en este entrefilete sin firma:

"Nuestro estimado colega de ésta, La Vanguardia, es el diario de las rarezas.

Despotrica contra los toros, por creer que el taurino espectáculo es la culpa de todos males que pesan sobre nuestra desgraciada patria; acoge en sus columnas todos cuantos artículos buenos o malos (generalmente son malos) tengan por tema decir pestes de los toros; uno de sus directores (La Vanguardia tiene dos) es enemigo de la fiesta nacional, a él en su mayor parte se debe que se prive a muchos suscriptores aficionados a esta fiesta, de las revistas que debía publicar, ya que un diario se debe a sus lectores y no a las ideas de sus directores, pero sin embargo este enemigo acérrimo de las corridas, pensando sin duda que una cosa es predicar y otra... escribe un Busca buscando [el título de las columnas de tema costumbrista de Boixet] lo firma con su tan conocido pseudónimo Juan Buscón y lo publica... en Don Jacinto, uno de los semanarios taurinos más leídos de España y populares de España.

Vean ahora, pues, si este señor Juan Buscón no merecería lo que yo me sé"10.

Podría tratarse, claro está, de un intento de salvar la imagen de la familia Opisso ante los lectores del semanario (poco después el popular dibujante Ricard Opisso se hizo perdonar que colaboraba en revistas contrarias a las corridas, ilustrando la portada del almanaque de La Fiesta Nacional de 1905), pero la acusación contra Boixet no fue desmentida. Quizás el hecho de que el diario siguiese publicando anuncios de las corridas, hacía pensar a los taurófilos que se trataba de una arbitrariedad de la dirección, más que de una declaración de principios empresarial. Parece difícil, no obstante, separar ambas cosas, sobre todo porque el diario había iniciado un acercamiento al catalanismo cultural incorporando a los críticos Yxart, Sardà y Casellas. Cuando en 1906 Godó convirtió la sala de mandos de la calle Pelayo en un triunvirato con el fichaje de Miquel dels Sants Oliver, de quien vimos que era un detractor de la tauromaquia, no hubo dudas de cuál sería la posición del diario en los años siguientes.

Entre los diarios en castellano otro caso singular fue el de El Diluvio, el diario republicano por antonomasia en el primer tercio de siglo, en el cual coexistían la adhesión a las corrientes ideológicas que condenaban las corridas y la necesidad de informar sobre un espectáculo atractivo para muchos de sus lectores. El antitaurinismo del diario tenía hondas raíces y en 1858, a los pocos días de aparecer el primer número con el título de El Telégrafo, uno de sus fundadores, Fernando Patxot, escribió una contracrónica de una corrida celebrada en la plaza de la Barceloneta ${ }^{11}$. La indiferencia

\footnotetext{
${ }^{10}$ Sin firma (10 de septiembre de 1904). "Noticias". La Fiesta Nacional.

${ }^{11}$ Ortiz de la Vega (pseud. de Fernando Patxot) (23 de noviembre de 1858). "Corridas de toros". El Telégrafo.
} 
hacia la "fiesta" se mantuvo un tiempo, pero en 1879, al ser refundado como El Diluvio, el diario publicó una crónica de ambiente de una tarde de toros en el Torín: "nos creemos trasladados a doscientas leguas de distancia; aquel público no es nuestro público; aquellos modales no son los de nuestro pueblo. Hasta el idioma es distinto. El catalán no tiene vocabulario tauromáquico"12. El Diluvio trataba de minimizar el hecho de que, a raíz de la rivalidad entre "Lagartijo" y "Frascuelo", el toreo se había popularizado considerablemente en Barcelona.

La misma línea irónica adoptada en aquella época por Rossend Arús, de quien ya hemos hablado, fue seguida unos años más tarde por El Diluvio. Pasada la etapa más convencional de los revisteros Mauricio Vidal (Rehilete) y Josep Costa Casanovas (Rigores), la sección fue asignada a Adolfo Marsillach Costa, quien adoptó un pseudónimo de resonancias taurinas que después se haría famoso por sus posiciones anticatalanistas (El Maleta Indulgencias). En sus crónicas solía citar a catalanistas a los que distinguía entre el público, lo que provocó el desmentido de unos redactores del semanario Joventut que se sintieron aludidos ${ }^{13}$. Las reseñas de Marsillach, que admitía no saber de técnica taurina, rezumaban desinterés por unas corridas que, a su entender, sólo "fabrican bárbaros" ${ }^{14}$. Ello coincidió con un rebrote de las campañas antitaurinas, que el diario, opuesto por principio al inmovilismo de los sectores más tradicionales, no podía ignorar. El alma del movimiento abolicionista era el histórico republicano Tiberio Ávila, un catedrático de historia que siendo diputado por Barcelona en 1873 ya había propugnado la desaparición de las corridas, y que en 1894 apoyó una proposición parlamentaria en el mismo sentido. La alianza entre reformistas sociales y catalanistas contrarios a las corridas, favoreció que Tiberio Ávila fuese elegido concejal por la candidatura catalanista (1901), y marcó el camino para que el diario republicano diese su apoyo formal a la causa antitaurina.

Al día siguiente del famoso mitin abolicionista celebrado en el Teatro Principal, el 13 de enero de 1901, con la presidencia del doctor Robert, El Diluvio publicó una crónica anónima de gran extensión (páginas 4 a 7) que reflejó con ecuanimidad los discursos de los organizadores. El Diluvio remarcó que, al anunciarse que el Orfeó Català era una de las entidades que se adherían al acto, un sector del público prorrumpió en gritos de “iCarcas!, ¡Sacristanes!, ¡Fuera! ¡Fuera! y grandes silbidos”. Las protestas reaparecieron cuando un orador alabó los anatemas de la Iglesia a las corridas de toros. El estamento clerical, con el recuerdo siempre presente de la quema de conventos de 1835, desconfiaba de la tauromaquia o de fiestas populares como el carnaval por lo que tenían de descontrol popular. De hecho, la ley del descanso

\footnotetext{
12 Sin firma (19 de mayo de 1879). “Toros. Media corrida del 18 de mayo". El Diluvio (ed. mañana).

${ }^{13}$ El Maleta Indulgencias (15 de octubre de 1900). "La corrida de ayer". El Diluvio (ed. mañana). También "Novas". Joventut. 18 de octubre de 1900.

${ }^{14}$ Una explicación de la campaña por el propio Marsillach en "Tauro...tontos". El Diluvio. 17 de agosto de 1900.
} 
dominical de 1904, que prohibió cautelarmente organizar corridas en domingo, lo que podía significar la desaparición de éstas a medio término, fue interpretada por muchos taurinos como un intento del gobierno de Maura por congraciarse con los sectores católicos.

En paralelo, en 1901 debutó como crítico taurino de El Diluvio Jerónimo Serrano "Azares", quien siendo aprendiz en la imprenta del periódico empezó a ir a la plaza del Torín como ayudante del crítico de la casa. Al poco de pasar a la redacción como corrector de pruebas, le encargaron la sección taurina, que había perdido terreno respecto a las de cabeceras como Las Noticias, El Liberal, El Noticiero Universal o La Publicidad (que confirmando el esquema expuesto anteriormente, siguió reseñando corridas hasta que pasó a publicarse en catalán en 1922). También es posible que el diario necesitara de los ingresos de la publicidad taurina, pues las denuncias de Marsillach del mal estado de la enfermería del Torín, enemistaron a los gestores taurinos con el diario ${ }^{15}$. El nombramiento de "Azares", que inicialmente firmaba "Rigores chico" en homenaje a su mentor, pareció abrir una etapa de provisionalidad, pero su prosa mordaz le convirtió en el crítico más popular de Barcelona durante más de treinta años. "Azares" sería respetado por su independencia en un mundillo en que algunos toreros no dudaban en pagar el "sobre" a los periodistas para que los ensalzasen; en ocasiones, este dinero era rechazado por los críticos, pero otras iba a parar directamente a la tesorería del diario y el periodista tenía que someterse a las directrices empresariales. Hay un detalle tipográfico indicativo del tono conferido a las crónicas por "Azares", y, asimismo, del talante de un diario que no iba dirigido a lo que en el argot se denomina "lector de cejas altas". Si una corrida había fallado por culpa de unos toros mansos o demasiado bruscos, al día siguiente la sección "Toros" era rebautizada, con la misma tipografía de costumbre, "Bueyes".

El momento decisivo del debate taurino se produjo en 1905. El 10 de febrero se convocó en el Tívoli otro mitin abolicionista, que según los organizadores contó con la adhesión de más de mil quinientas asociaciones de toda España, pero en el que también participó un grupo de taurófilos que intentó boicotear el acto con interrupciones. En una carta al semanario La Fiesta Nacional, los alborotadores protestaron porque El Diluvio había dedicado mucho más espacio a la crónica del mitin abolicionista que a una carta de réplica que ellos habían enviado al diario. Reprochaban a la dirección de El Diluvio esta entradilla falsamente equidistante: "En prueba de imparcialidad ponemos frente a frente a las fuerzas de beligerantes, a fín de que la ley se incline donde haya más peso"16. En contra de lo que algunos esperaban, en abril de 1905 el gobierno del partido liberal revocó la prohibición de celebrar las

\footnotetext{
${ }^{15}$ Azares (1 de noviembre de 1933). "Los Toros". El Diluvio.

${ }^{16}$ Sin firma (25 de febrero de 1905). "Por la fiesta española". La Fiesta Nacional.
} 
corridas en domingo. El Diluvio, que nunca había sido un gran entusiasta de las corridas, devino en el diario de referencia de los taurófilos barceloneses.

Las crónicas sólidamente argumentadas, pero de estilo desenfadado, de "Azares" contrastaban con las del otro pope de la crítica de antes de la guerra, Ventura Bagüés ("Don Ventura"), un aragonés que se había formado como periodista en Bilbao y que a principios de los años veinte se incorporó a la redacción del diario lerrouxista El Día Gráfico. Autor de numerosas monografías históricas, la prosa más esquemática y descriptiva de "Don Ventura", con el añadido de algún ripio ocasional, evocaba la de los revisteros del ochocientos. Las referencias historicistas, que podían ir desde el linaje de una ganadería hasta la genealogía de un lance o el recuerdo de una tarde histórica, eran aceptados por los lectores porque la "fiesta" gozaba de un nuevo estatus cultural desde que pintores como Ramón Casas o el joven Picasso incluyeron el tema taurino en sus primeras exposiciones, y los intelectuales de la generación del 98, que habían considerado las corridas como una de las causas del atraso del país, se acercaron a ellas atraídos por la personalidad de los toreros de la "edad de oro". El mismo Santiago Rusiñol, considerado un epígono catalán de la generación del 98, había sido muy crítico con algunos rasgos de la psicología castellana, pero en la novela "El català de la Mancha" (1917), inspirada en buena medida en el torero leridano Eugenio Ventoldrá (Rusiñol, 2014: 213-214), describió cómo un anarquista utópico catalán fracasaba en el intento de adoctrinar a los vecinos de un pueblecito manchego, y además le salía un hijo torero.

\subsubsection{Prensa satírica}

Como ya se ha apuntado anteriormente, el semanario L'Esquella de la Torratxa utilizó en alguna ocasión la información taurina como telón de fondo para ironizar sobre el ambiente social o político. Otro recurso habitual era caricaturizar a los políticos españoles del XIX o principios del XX como toreros, picadores o cualquier otro oficio que pudiera relacionarse con los clichés flamenquistas. Pero además, ante el desarrollo de la "fiesta" como espectáculo de masas en Barcelona, algunas publicaciones satíricas intentaron combatir el fenómeno parodiando las corridas como algo ridículo o bárbaro, según el enfoque de los humoristas. Al inaugurarse en 1914 la plaza El Sport, ampliada y rebautizada en 1916 como Plaza Monumental para acoger la etapa más gloriosa del toreo moderno, L'Esquella de la Torratxa dedicó un número casi monográfico la tauromaquia, pero el caricaturista Josep Costa Ferrer ("Picarol”) aportó sin pretenderlo una clave para entender el arraigo de las corridas en Barcelona; acodado en un burladero, uno de sus personajes más característicos, un plutócrata con los estilemas propios de las caricaturas del gran dibujante berlinés Grosz (chistera, gafas negras) comentaba con melancolía la clásica estampa del caballo de picar desventrado por los pitones del toro: "Llàstima de budells... Si no fossin tan estripats, encara servirien per a fer butifarres". [Lástima de intestinos... Si no estuviesen tan 
destripados, aún servirían para hacer butifarras] ${ }^{17}$. Mientras catalanistas y librepensadores regeneracionistas soñaban con suprimir las corridas, nunca faltaban negociantes catalanes seguros de poder lucrarse con el espectáculo taurino.

\subsubsection{Prensa especializada}

En 1927 la gestión de la Monumental fue encomendada al empresario del sector bovino Pedro Balañá Espinós, quien una década antes había sido concejal por la Unió Federal Nacionalista Republicana (conocida como "esquerra catalana"). En sus tiempos de concejal fue uno de los propietarios del órgano del partido, El Poble Català, una inversión que le sirvió para catapultarse políticamente y que le enseñó cómo tratar con periodistas. Uno de los secretos de Balañá para triunfar empresarialmente fue su conexión con los cronistas locales. Además de mantener una relación amigable con "Azares" y "Don Ventura", influyó sobre el importante semanario La Fiesta Brava, y tampoco fueron insensibles a sus encantos empresariales los comentaristas de la prensa radical Miquel Fabregat y Fernando Gudel Fillat ("Fegufi") o los diferentes críticos que pasaron por el vespertino El Noticiero Universal. En contraste con los parabienes de este grupo, Balañá hubo de soportar las maledicencias del semanario Oro y Plata, del que se decía que se había enfrentado con Balañá al negarle éste unos pases de favor a los redactores ${ }^{18}$.

Desde finales del siglo XIX en Barcelona se habían publicado numerosas revistas taurinas que tenían en común su corta tirada, su vida efímera (la excepción fueron EI arte del toreo y La Fiesta Nacional, ya al despuntar el siglo XX) y el estar animadas por algún personaje con ambiciones en el negocio taurino (Mariano Armengol o Eduardo Pagés dirigieron sus propias revistas, aunque también lo hizo un crítico del prestigio de Juan Franco del Río "Franquezas"). Sobre ellas planeaba la sospecha de que su tono airado era una estratagema para coaccionar a los toreros a insertar publicidad, pero ese no era el caso de una revista sólidamente implantada como Oro y Plata; su visión catastrofista de la gestión de Balañá induce a pensar que Oro y Plata tenía como "caballo blanco" a algún aspirante al arrendamiento de las plazas que pretendía desgastar la gestión de Balañá con campañas de opinión.

El empresario taurino fue también el destinatario de las diatribas de los consabidos semanarios irreverentes y minoritarios, entre los que destacaba La Protesta Taurina, que solía dibujar unas viñetas con un negociante tocado con sombrero hongo y habano en ristre apellidado "Orgañá", lo que remitía a la vez a "Balañá" y al verbo "ordeñar" (Balañá presidía el gremio de vaqueros pero la imagen se prestaba a otras interpretaciones). Por el contrario, esta publicación jaleaba a Eduardo Millán "Don Eduardo", el crítico de la Hoja oficial de la provincia de Barcelona, que comenzó a

\footnotetext{
${ }^{17}$ L'Esquella de la Torrratxa. 27 de marzo de 1914.

${ }^{18}$ La Semana Taurina. 6 de abril de 1930.
} 
editarse en 1926 con fines benéficos. De filiación monárquica, Millán estaba en sintonía con la apuesta del régimen de Primo de Rivera por la tauromaquia (se organizaron diversos festejos coincidiendo con la Exposición Internacional de 1929), pero en sus crónicas no ahorraba punzantes observaciones por la escasa calidad del ganado contratado. "Don Eduardo" fue destituido al proclamarse la República y su sustituto bajaría el tono de las críticas a Balañá.

\subsubsection{Prensa catalanista}

Entretanto, la intelectualidad catalanista, siguiendo el modelo trazado por la "Renaixença", seguía viendo el toreo como una expresión de los valores anacrónicos de una cultura foránea. A esta visión reduccionista no le faltaban argumentos para litigar con los taurófilos. Uno de los grandes matadores de comienzos de siglo, Ricardo Torres "Bombita", que mantenía una relación sentimental con la hija de un fabricante de tejidos manresano, leyó el primero de julio de 1914 en El Poble Català, órgano del catalanismo republicano, un comentario irónico que juzgó ofensivo para su amada. "Bombita" se presentó en la redacción del rotativo, donde propinó varios bastonazos al director y esgrimió una pistola antes de ser reducido por los redactores. El diputado regionalista Pedro Rahola y el pintor Casas Abarca intercedieron por "Bombita" en el juzgado de guardia, y el caso no fue a mayores, pero el incidente no contribuyó a mejorar la reputación de los matadores entre los barceloneses biempensantes.

Al igual que los diarios en catalán de los albores de siglo, la prensa vinculada a los partidos catalanistas de la Segunda República también omitía la actualidad taurina, y ello a pesar de que el primer gobernador civil del nuevo régimen, Lluís Companys, acudió a un palco de la Monumental a los pocos días de asumir el cargo ${ }^{19}$. Se podían publicar anuncios de las corridas importantes, como hacían La Humanitat o L'Opinió; acudir asiduamente al palco reservado en la Monumental al Presidente del Parlament, como solían hacer los hijos del presidente Casanoves y de Carles Pi-Sunyer, otro líder de Esquerra Republicana (Cirici, 1973: 92); se podía incluso acompañar al alcalde de Madrid a la Monumental la misma tarde en que se celebraban los Jocs Florals, el gran certamen poético del catalanismo, como se permitió el propio Casanoves"20. Ahora bien, informar del desarrollo de las corridas en catalán, contribuyendo así a su prestigio cultural, suponía rebasar un límite que podía merecer la reprobación de los correligionarios o competidores catalanistas.

Del mismo modo que la Constitución de La Habana de 1928, elaborada por sectores separatistas, proclamaba en su artículo 52 la supresión en una supuesta Cataluña independiente de "les curses de toros, les exhibicions de boxa i tot esport que tendeixi a embrutir el poble" [las corridas de toros, las exhibiciones de boxeo y todo deporte

19 "Toros". El Diluvio. 21 de abril de 1931.

20 “Manxiules". D.I.C. (Defensa Interessos Catalans). 14 de mayo de 1932. 
que tienda a embrutecer al pueblo], o que un intelectual conservador como Bofill i Mates, en su ensayo póstumo "Una política catalanista" (1933), acusaba al estado español de fomentar "una veritable separació moral" al ensalzar, en otras actividades, "les curses de braus a la categoria de festa nacional" (Bofill i Mates, 1986: 139), la posición ante el tema entre las nuevas promociones intelectuales siguió el camino trazado $^{21}$. En junio de 1930 el nuevo semanario Imatges, que aspiraba a ser un altavoz de la modernidad cosmpolita, publicó un reportaje a doble página de Josep Maria de Sagarra, quien reconocía ir asiduamente a los toros pero describía los aspectos más macabros de una tarde en la Monumental ${ }^{22}$. Y en 1932 el poeta J.V. Foix arremetía en La Publicitat contra la moda taurina en tierras catalanas: "A Barcelona, els veïns de la plaça d'Espanya i de la «Monumental» veuran bastir, a l'indret on hi ha avui les plazas que recorden els segles de pobresa material i espiritual del país, escoles i gimnasos [En Barcelona, los vecinos de la plaza España y de la Monumental verán edificarse, en el lugar donde hoy hay las plazas que recuerdan los siglos de pobreza material y espiritual del país, escuelas y gimnasios]"23.

La presencia en los tendidos de la Monumental de la plana mayor del semanario La Rambla, próximo a Esquerra Republicana, desató algunas chanzas en la sección de indiscreciones de Mirador, situado en la órbita de Acció Catalana ${ }^{24}$. Para el catalanismo de raigambre ser aficionado a los toros podía delatar una identidad sobrevenida, un lerrouxismo encubierto bajo capas de oportunismo. La única incursión en el tema de Sagarra en tiempos de la República, consistió en escandalizarse porque, después de una tarde apoteósica, unos aficionados pasearon a hombros a "Carnicerito de Méjico" por las Ramblas hasta su hotel. Si bien desde mediados del XIX el negocio taurino estaba centralizado en torno al café Lyon d'Or y las taquillas del Teatro Principal, ambos situados al final de las Ramblas, Sagarra tildaba la incursión de provinciana y opuesta al espíritu barcelonés. La almendra del artículo surgía en la última frase:

Seria tristíssim i fatal per al nostre país que inconscientment, tot el negre llevat lerrouxista s'apoderés de la sang de moltíssims desenfrenats que van cridant visca Catalunya!, i no s'adonen que cada vegada tenen el cor més lluny de Catalunya. ${ }^{25}$.

\footnotetext{
${ }^{21}$ Josep Pla (3 de mayo de 1927). "Misèria de les curses de braus". La Publicitat.

22 J.M. de S. (16 de junio de 1930). "La part més negra dels "Toros"”. Imatges.

23 J.V. Foix (24 de septiembre de 1932). “Toros a Cervera!”. La Publicitat.

24 "Mirador indiscret". Mirador. 21 de abril de 1932.

25 [Sería tristísimo y fatal para nuestro país que inconscientemente, toda la negra levadura lerrouxista se apoderase de la sangre de muchísimos desenfrenados que van gritando iviva Catalunya!, y no se dan cuenta que cada vez tienen el corazón más lejos de Catalunya]. Josep Maria de Segarra (27 de mayo de 1933). "Sobre el flamenquisme". La Publicitat.
} 
Este rechazo intelectual explicaría por qué, pese a sus vínculos con familias políticas distintas del catalanismo republicano, siendo ya presidente de la Generalitat Companys no volvió como espectador a la Monumental, hasta la corrida a beneficio del Comité de Milicias Antifascistas del 16 de agosto de 1936. El presidente de la Generalitat y el jefe de la Columna Durruti, Ricardo Sanz, tomaron la palabra para agradecer el dinero recaudado, pero al cabo de unos días el militar anarcosindicalista se vio impelido a dar explicaciones en el órgano cenetista Solidaridad Obrera, que siempre había condenado el espectáculo taurino por su carácter capitalista: "Ahora bien; yo no soy partidario de la supresión por decreto, o por la violencia, de las corridas de toros. Nosotros, los anarquistas, hombres libres, en todo el valor de la palabra, no creemos en la eficacia de la coacción. Las corridas de toros han de ser abolidas cuando así lo exija la conciencia del pueblo"26.

\subsubsection{Prensa franquista}

Justo al acabar la guerra también se celebró una "corrida patriótica" en Barcelona, en este caso para festejar la victoria franquista, y La Vanguardia Española continuó con su tradición de no informar de los eventos taurinos. Pero con el nombramiento a finales de abril de 1939 del director Luis de Galinsoga, ingresó en la redacción como subdirector Eduardo Palacio-Valdés y Fernández de Córdoba, quien en los años treinta había ejercido la crítica taurina en $A B C$, relevando al prestigioso Gregorio Corrochano, aunque dejó el diario madrileño en 1934 por motivos ignorados. "Ese mal crítico de toros, desacreditado en Madrid, a quien yo traje a Barcelona", habría comentado Galinsoga después de que Palacio-Valdés no se solidarizase con él por su destitución en 1960 (Voltes, 2004: 353). Poniendo fin a décadas de silencio taurino del diario de la familia Godó, "E.P." (las iniciales con que firmaba Palacio-Valdés) debutó en la corrida del 28 de mayo de 1939, afirmando que la interpretación del "Cara al sol" por el público "fue la nota más soberbiamente emotiva"27.

El triunfalismo de las corridas conmemorativas o patrióticas no evitaba que el mundo del toreo continuase siendo terreno abonado para la picaresca. A modo de ejemplo, y por lo que se refiere al periodismo, continuó el pago del "sobre" a los revisteros por parte de los toreros, un asunto que salpicó a Palacio-Valdés. El historiador Pedro Voltes Bou, en tiempos redactor de mesa de La Vanguardia Española, desvelaría que el crítico:

\footnotetext{
"implantó una aduana tan rigurosa que en cierto momento tuvo que intervenir en ella el propio gobernador civil Antonio Correa. En efecto, Manolete se negó según se dijo- a abonar el canon que le imponía el llamado Palacio Valdés y este

${ }^{26}$ José Carranza (23 de agosto de 1936). “Dice Ricardo Sanz. Las corridas de toros han de ser abolidas cuando así lo exija la voluntad del pueblo". Solidaridad Obrera.

27 “En la plaza de toros de Las Arenas. Un mano a mano". La Vanguardia Española. 30 de mayo de 1939.
} 
se mantuvo firme en exigirlo. Se dio el caso chusco de que el gobernador hiciera de árbitro a propósito de asunto tan maloliente, para que las pretensiones del revistero taurino quedasen algo moderadas, a cambio de lo cual renació la paz" (Voltes, 2004: 282).

El episodio es revelador de la conexión con el sector taurino del gobernador civil Correa Veglison, quien promovió numerosas corridas de significación falangista.

\subsubsection{Prensa falangista}

En 1942, mientras que el gobernador y jefe provincial del Movimiento Antonio Correa Veglison se dejaba ver a menudo en la barrera del 2 de la Monumental (y no en los palcos de honor, como hacían los capitanes generales en muestra de despótica autoridad), el órgano falangista Solidaridad Nacional cuestionaba las triquiñuelas de Balañá, la calidad de las ganaderías o la categoría de las nuevas figuras del toreo. Es difícil saber si esta dicotomía obedecía a tensiones internas entre la "vieja guardia" y un personaje más bien oportunista como Correa; pero es probable que hubiera un reparto de papeles bien calculado, dado que el mordaz crítico que firmaba "Juan Jara" era nada menos que el subdirector Antonio Álvarez Solís -padre del periodista que firmaba con este nombre aún a comienzos de este siglo-, que hacía poco había recalado en "la soli" procedente de la dirección de La Voz de Galicia.

Álvarez Solís, formado periodísticamente en el católico El Debate, y como taurino entre la rigurosa afición madrileña, pretendía encarnar la figura del joseantoniano puro que preconizaba la regeneración de la corrompida vida española, pero su campaña contra el fraude en el toreo (coincidente con la del diario falangista madrileño Arriba) acabó repentinamente cuando un puñado de orejas, rabas y patas cortados por "Manolete" le erigieron en un ídolo en Barcelona, a la vez que era adoptado como arquetipo moral por la nueva España. El régimen franquista comprendió que la "Fiesta nacional" podía ser un magnífico vehículo de propaganda y de control de la sociedad, sin olvidar que era un buen reclamo para el turismo de posguerra. En las academias de baile y los cabarets frecuentados por las clases acomodadas (El Cortijo, La Rosaleda) se puso de moda, con el éxito de la copla o las "españoladas" cinematográficas, una version algo estereotipada del folklore andaluz, que en Barcelona tenía su epicentro en el Hotel Oriente (donde solía parar Manolete) y los "tablaos" flamencos de aquella Rambla baja que Sagarra no quería ver profanada.

Álvarez Solís acabaría escribiendo un par de folletos que ensalzaban a los toreros más famosos, pero no fue el único que se adaptó a la moda del nuevo flamenquismo. El semanario burgués Destino estrenó sección taurina en 1944, aprovechando el ingreso en la redacción de Néstor Luján Fernández ("Puntillero"), hijo de militar y con experiencia en la prensa falangista universitaria. Luján sorprendió a los entendidos por su sensibilidad plástica y amplia perspectiva histórica (escribió una historia del toreo 
considerada una referencia en la materia), a la vez que mantenía las distancias con Balañá y no se dejaba deslumbrar por los ases del momento. Por su parte, el empresario, con una fuerte presencia publicitaria en los diarios barceloneses, recompuso su corte de revisteros de antes de la guerra. El veterano "Don Ventura" fue repescado, pese a su trayectoria en la prensa republicana, para la Hoja del Lunes y el semanario madrileño El Ruedo; Fernando Gudiel ("Fegufi") fue contratado por el reaparecido Diario de Barcelona; y José Soler Poch, un abogado carlista que siempre se había movido por los ambientes taurinos, se encargaría de las crónicas en El Correo Catalán con el pseudónimo de "Domingo".

El tono crítico se mantuvo, como excepción a la norma, en la prensa falangista. Con el mismo ímpetu que había mostrado durante un tiempo Álvarez Solís, le sustituyó Manuel Vela Jiménez, un ex alférez provisional que había escrito una novela ambientada en las capeas de pueblo que fue masacrada por la censura. Las admoniciones de Vela Jiménez al empresario Balañá o al entorno de "Manolete" insinuaban que el "establishment" taurino había reproducido los vicios del liberalismo político y del capitalismo corrupto, con el añadido de que ahora surgía una alternativa creíble al maestro cordobés. La devoción de Vela Jiménez por el mejicano Carlos Arruza, mostraba la conexión falangista con un público popular que aclamaba desde los tendidos de sol a un nuevo ídolo no adulterado por el mercantilismo. El rechazo a "Manolete" de algunos críticos demagogos desapareció con la muerte del torero en Linares en 1947, que desató una especie de auto sacramental en toda España. El mismo Vela Jiménez, que gustaba de componer versos, contribuyó con una sentida elegía ${ }^{28}$.

Entretanto el nuevo gobernador civil Bartolomé Barba, desmarcándose del triunfalismo fomentado por su antecesor Correa, endureció la aplicación del reglamento taurino y ordenó un cambio en la presidencia de las corridas. Históricamente las corridas eran presididas en Barcelona por concejales, pero a raíz de unos incidentes registrados en Las Arenas el 12 de junio de 1904, los concejales, hartos de que los escándalos taurinos saboteasen su carrera política, renunciaron a presidir las corridas. La tarea recayó en altos funcionarios del gobierno civil y alguna vez, como se hacía en Madrid para garantizar el orden público, en agentes de policía (el controvertido jefe de policía Tressols presidió, como mínimo, alguna corrida en $1907^{29}$ ). En 1946 Barba ordenó que la presidencia pasara a la jurisdicción de los comisarios de policía, lo que reforzó la autoridad del presidente, que ahora podía imponer severas multas a los picadores que incumpliesen el reglamento o a los espectadores denunciados por vandalismo. La contrapartida negativa fue que la

\footnotetext{
${ }^{28}$ Manuel Vela Jiménez (6 de septiembre de 1947). "Elegía a "Manolete"”. Solidaridad Nacional. Manuel Vela Jiménez (4 de septiembre de 1947). "Coplas a Manolete". Solidaridad Nacional.

29 “Toros en Barcelona”. La Fiesta Nacional. 12 de septiembre de 1907.
} 
prensa dejó de cuestionar la dirección de la lidia por los presidentes, que pasó a ser casi siempre favorable a los intereses de Balañá.

De acuerdo con el reglamento, el presidente contaba con un asesor, cuyos gastos eran sufragados por la empresa. En Barcelona los asesores solían ser banderilleros o toreros retirados que dependían económicamente de Balañá para poder subsistir, y que se lo pensaban mucho a la hora de aconsejar al presidente que ordenase devolver un toro defectuoso al corral (la empresa tenía que pagar el correspondiente sobrero) o negase una oreja a un torero protegido por el empresario. La impunidad con que Balañá se desenvolvía se vio enturbiada por una serie de circunstancias que concurrieron en 1953. Si hasta entonces no había sido castigado de forma notable por ninguna irregularidad, ahora se vería cuestionado por un cambio súbito de la legislación taurina. Para que no degenerase un espectáculo que podía resultar atractivo para el naciente turismo internacional, el Ministerio de la Gobernación adoptó algunas medidas que pretendían combatir las corruptelas del "lobby" taurino. En esta misma dirección el conocido torero Antonio Bienvenida y el semanario madrileño La Actualidad Española, vinculado a los tecnócratas reformistas del Opus Dei, provocaron un gran revuelo al denunciar el escándalo del "afeitado" de los pitones. Algunas informaciones señalaban al empresario de la Monumental ${ }^{30}$, lo que obligó a intervenir al gobernador civil Felipe Acedo Colunga, famoso entre sus subordinados y los prohombres barceloneses por su carácter atrabiliario y ramalazos de populismo ${ }^{31}$. Después de una tarde de gran expectación en que el público salió frustrado por un ganado sin trapío, el gobernador condenó a Balañá y a los apoderados de los toreros a pagar una multa y a pasar la noche en el calabozo de la Jefatura policial ${ }^{32}$.

Las restricciones periodísticas podían tener consecuencias aún más graves. Rafael López Chacón, crítico del vespertino falangista La Prensa que había encontrado en la rivalidad Manolete-Arruza el contexto adecuado para exhibir su brillante prosa abarrocada y unos conocimientos enciclopédicos de la lidia o los encastes ganaderos (sus crónicas de la temporada 1945 fueron recopiladas en el libro "Toros en Barcelona"), tropezaría con un Capitán General que profesaba una admiración desmedida por el novillero onubense Antonio Borrero "Chamaco", y no se privaba de gesticular contra los presidentes que perjudicaban a su protegido. El 15 de octubre de 1956 "Chamaco" tomó la alternativa en la Monumental, pero el triunfador de la tarde fue Antonio Ordóñez, quien se llevó dos orejas de un toro "siquiera no prosperase alguna indeseable interferencia". Esta frase escrita por López Chacón fue interpretada

\footnotetext{
30 Julio de Urrutia (25 de junio de 1953). "Siguen los fraudes en la fiesta española. También se ha conseguido "Morfinizar" a los toros". La Actualidad Española. E. P. (Eduardo Palacio-Valdés) (3 de julio de 1953). "La fiesta de los toros. ¿"Morfina, o cardiazol"?". La Vanguardia Española.

31 "Nota de la Jefatura Superior de Policía". La Vanguardia Española. 7 de julio de 1953; Julio de Urrutia (9 de julio de 1953). "Barcelona veta la morfina”. La Actualidad Española.

32 “Una nota del Gobierno Civil”. La Vanguardia Española. 11 de septiembre de 1953.
} 
por el Capitán General, el chamaquista Juan Bautista Sánchez, como un reproche a sus gestos de protesta por la concesión de las orejas a Ordóñez. El periodista fue encarcelado en el castillo de Montjuich y se abrieron diligencias por la justicia militar. La profesión periodística se movilizó y consiguió la libertad provisional para el crítico, y el expediente fue sobreseído al morir accidentalmente el Capitán General ${ }^{33}$. Entrevistado en 1970, el periodista aseguraba que con la frase "alguna indeseable interferencia" no pretendía atacar al militar, y que, además, hubo un malentendido ("no quise decir "indeseable" sino "desfavorable"")34). En una entrevista posterior añadió que el incidente había sido provocado por un error del linotipista (Fabre, 2017: 39).

Balañá continuó hasta su muerte, en 1965, con su política de alternar pequeñas corruptelas y grandes carteles. Él argumentaba que programar corridas a mansalva era la única manera de crear afición, y que ello implicaba comprar la camada entera a algunos ganaderos, con lo que ello implicaba de altibajos en el ganado. Por otra parte, las ganancias en taquilla por la aparición de "Chamaco" acentuaron los rasgos más cínicos de la gestión de Balañá, que no dudó en intimidar a las escasas voces críticas. Mariano de la Cruz, el corresponsal en Barcelona de la Hoja del Lunes madrileña, fue uno de los pocos que se atrevieron a denunciar que el fenómeno del "chamaquimo" agravaba la práctica del "afeitado". Denunciado en los tribunales por un ganadero de confianza de Balañá, Cruz fue condenado a una multa de cincuenta mil pesetas que solo fue retirada cuando la crítica y las peñas madrileñas se movilizaron en su defensa (Boix-Espada, 2002: 198). Psiquiatra de profesión y amigo personal de un Luján que había abandonado la crónica taurina, Cruz sería un preciso y ecuánime crítico de $L a$ Vanguardia en la Transición, después del interregno de Julio Ichaso, un antiguo secretario de Galinsoga.

\subsubsection{Prensa democrática}

La nota más destacada del último cuarto de siglo fue la aparición de crónicas taurinas escritas en catalán. Hubo, simultáneamente, algún intento de reivindicar el toreo desde las filas del catalanismo. En un artículo aparecido en la revista Oriflama a finales de 1977, el escritor y político Jaume Miravitlles, que en los años de la República había acudido asiduamente al palco de Joan Casanoves en la Monumental, señaló la paradoja de que mientras el toreo estaba en crisis en Barcelona, en la Cataluña francesa se había promocionado para así remarcar las particularidades meridionales respecto a París ${ }^{35}$. Y en el diario Avui, un cronista tan respetado como Andreu Avel-lí Artís "Sempronio", hijo de un periodista que ocasionalmente hizo de revistero, recordó

\footnotetext{
${ }^{33}$ Archivo del Tribunal Militar Territorial III de Barcelona. Expediente 1.231. Año 1956.

${ }^{34}$ Ricardo Huertas (19 de abril de 1970). "Veteranos del periodismo taurino. Don Rafael López Chacón, itálico y poeta". Solidaridad Nacional.

35 Jaume Miravitlles (8 de octubre de 1977). "La cursa de braus, reivindicació catalanista". Oriflama.
} 
la gran aportación catalana a la fiesta: Eduardo Pagés y Pedro Balañá son dos de los empresarios españoles más importantes del siglo $X^{36}$.

Aún a mediados de 1992, Néstor Luján, recordando sus tiempos de crítico taurino, evocó con nostalgia la figura de Manolete en el suplemento dominical de EI Observador, un diario próximo al nacionalismo convergente ${ }^{37}$. Asimismo, la contratación de Antoni Santainés como crítico del citado diario catalanista Avui, apuntaría a una tímida reivindicación catalana de la "fiesta". Sin embargo, en la incorporación de Santainés, condiscípulo de Jordi Pujol en el Colegio Alemán, influyó que aquel fue a ver al político a su despacho de Banca Catalana -según nos explicó el mismo Santainés ${ }^{38}$ - para pedirle la plaza de crítico en el diario que estaba a punto de empezar a publicarse. Otro motivo de coincidencia era la amistad de Santainés con un gran torero de los años treinta, Domingo Ortega (escribió su biografía autorizada), de quien Jordi Pujol ha comentado más de una vez que su padre, Florenci, era un gran admirador. En cualquier caso, un lector de calidad como el escritor Artur Bladé i Desumvila criticó la apuesta taurina del diario: "Jo tenia entès que el silenci dels nostres diaris d'abans de la guerra pel que toca a dit espectacle -o el que sigui- era una manifestació més del "fet diferencial" [Yo tenía entendido que el silencio de nuestros diarios de antes de la guerra en lo tocante a dicho espectáculo -o lo que sea- era una manifestación más del "hecho diferencial"] $]^{39}$.

En el ámbito de la prensa cercana al partido socialista, a mediados de los años ochenta el arquitecto Antoni González Moreno-Navarro asumió la rúbrica taurina de Diari de Barcelona. En sus reseñas y en su libro "Bous, toros i braus: una tauromàquia catalana" (1996), haría una investigación casi etnográfica, recopilando la terminología taurina en catalán. En una reciente biografía dedicada a "Chamaco", González sostiene que detrás de las campañas de la prensa madrileña de mitad de siglo contra las corruptelas de Balañá, había no solo un espíritu moralista, sino también un deseo de favorecer los intereses económicos de la plaza de Las Ventas, para la cual la Monumental llegó a ser una notable competidora (González, 2016: 95-96). Pero la decadencia de la Monumental en el último cuarto de siglo, a causa principalmente de los nuevos hábitos de ocio y el efecto de las campañas antitaurinas, abocaron a la "fiesta" en Cataluña a una crisis que tendría su reflejo en la prensa barcelonesa. La rápida desaparición de la información taurina en catalán (con excepción de la web "vadebraus.com") mostraría las sinergias de los nacionalistas catalanes con los grupos antitaurinos, que desembocarían en la abolición de las corridas, después de una ajustada votación en el parlamento autonómico en 2010.

\footnotetext{
${ }^{36}$ Sempronio (3 de julio de 1995). "Som els catalans al-lèrgics als toros?". Avui.

${ }^{37}$ Néstor Luján (14 de junio de 1992). “El túnel dels anys quaranta. Manolete”. Set Dies. El Observador.

${ }^{38}$ Entrevista grabada a Antoni Santainés Cirés. 22 de febrero de 2013.

${ }^{39}$ Artur Bladé i Desumvila (4 de junio de 1976). "Bústia. Toros". Avui.
} 


\subsection{Los toros en la prensa barcelonesa de comienzos del siglo XXI}

Al margen de la literatura reciente que describe el clima político que precedió a la abolición de los toros en Cataluña (Boix, 2011: 24-43) y el tratamiento de esta cuestión en los principales periódicos españoles (Carballa-García Gonzalez, 2014: 9-15), una tesis doctoral publicada en 2016 detalla la progresiva marginación de la información taurina en los dos principales rotativos catalanes (Castelló, 2016: 473-550), llegándose a la supresión en el caso de El Periódico de Catalunya. En la decantación antitaurina de este medio influyó, después de unos años en que incluso explotó el fenómeno de los toreros asiduos a la "prensa couché" -su cronista taurino Soto Viñolo fue biógrafo de Rocío Jurado-, la aparición en 1997 de una edición del diario en catalán fuertemente subvencionada ${ }^{40}, y$, ya en un contexto de gran tensión política, la identificación de la tauromaquia con los gobiernos del PP. El professor Castelló Ribera disecciona la progresiva marginación de los contenidos taurinos en El Periódico de Catalunya (cambios de sección, predominio de la opinión sobre la información, supresión de las fichas de las corridas) que preludiaron el despido de Soto Viñolo después de las corridas de la Mercè de 2009 (Castelló, 2016: 414 y 691) y la consiguiente supresión de la información taurina. En plena sintonía con los postulados del gobierno tripartito catalán, el 26 de noviembre de ese mismo año El Periódico de Catalunya fue uno de los diarios que publicaron el editorial conjunto "La dignidad de Catalunya", que abogaba por mantener en su integridad el texto del Estatut catalán aprobado en 2006.

Sin alcanzar estas cotas de taurofobia, La Vanguardia siguió reseñando las corridas de la Monumental e incluso dedicó una amplia cobertura a acontecimientos como la reaparición en los ruedos españoles de José Tomás en Barcelona. Dada la presencia en la Monumental de numerosos aficionados del resto de España, incluyendo los invitados de grandes empresas con sede en Madrid, no puede descartarse que el notable despliegue de La Vanguardia fuese dirigido a unas élites madrileñas que tradicionalmente han considerado el diario del conde de Godó como un medio de referencia. Castelló Ribera detecta un aluvión de cartas de lectores antitaurinos publicadas en los días siguientes a la corrida, lo que según el autor denota que los responsables del diario "aprovecharon el interés informativo de un acontecimiento para poner sobre la mesa el debate taurino en Cataluña, haciéndose eco de partidarios y enemigos y provocando la reacción de los lectores" (Castelló, 2016: 560-564 y 598). En cualquier caso, las crónicas y los titulares más entusiastas de la prensa española respecto a José Tomás probablemente se publicaron en "La Vanguardia". Una nueva

\footnotetext{
${ }^{40}$ Solamente en 2010 la Conselleria de Cultura de la Generalitat subvencionó con 1.261.404'02 euros a la edición en catalán de "El Periódico de Catalunya" (E-noticies, 9-X-2011).
} 
paradoja de este periódico, tratándose del más influyente impulsor del proceso secesionista en la prensa escrita ${ }^{41}$.

\section{Conclusiones}

En nuestro análisis de cómo la prensa barcelonesa abordó a lo largo de siglo y medio la información sobre las corridas de toros celebradas en Barcelona, hemos visto cómo la prensa diaria en catalán, adscrita al catalanismo político, se abstuvo casi siempre de hacerlo, si bien algunas revistas satíricas en catalán, identificadas con el republicanismo más que con el catalanismo, reseñaban las corridas con el propósito de criticar a las autoridades que presidían los festejos o simplemente para ridiculizar a la tauromaquia.

En cuanto a la prensa en castellano, por lo general reseñaba las corridas, con la notable excepción de La Vanguardia, que al arrancar el siglo XX suprimió la información taurina de sus páginas. Los datos recogidos en nuestra investigación apuntan a un intento de los sucesivos directores (Sánchez Ortiz, Boixet, Oliver), respaldados por la propiedad, por aproximar La Vanguardia a las corrientes de opinión regeneracionistas y catalanistas. Este posicionamiento se tradujo en un apoyo a las campañas abolicionistas que tuvieron lugar a comienzos de siglo, que también tuvieron amplio reflejo en el diario republicano histórico El Diluvio, que sin embargo mantuvo la sección taurina e incluso se convirtió en un medio de referencia para los aficionados. El hecho de que el resto de cabeceras en castellano no siguieran el ejemplo de La Vanguardia (con excepción del órgano anarcosindicalista Solidaridad Obrera, ajeno a los espectáculos "capitalistas") tuvo que ver con los intereses de los lectores, pero también con los ingresos obtenidos por la publicidad de la empresa taurina de Pedro Balañá Espinós, un antiguo concejal catalanista que introdujo modernos métodos de gestión en las plazas de toros barcelonesas.

El tono general favorable a la empresa aumentó durante el franquismo, periodo en que la utilización propagandística de la "Fiesta nacional" hizo obligatoria la información taurina en todos los diarios, incluido el de la familia Godó, rebautizado La Vanguardia Española por orden de las autoridades. La nota discordante procedía de la prensa falangista, que arremetió contra los profesionales de la "fiesta" al considerar que éstos se regían por valores mercantilistas identificados con el liberalismo. El triunfalismo imperante entre los críticos barceloneses -los ataques a Balañá por corruptelas en la organización de corridas vinieron en su mayor parte de la prensa madrileña- no

\footnotetext{
${ }^{41}$ Manuel Trallero (28 de octubre de 2012). El Grande de España que quiere romperla. Crónica. El Mundo.
} 
impidieron una progresiva decadencia del espectáculo, manifestada en concesiones a los gustos de los turistas y, ya en democracia, en una menor atención de la prensa generalista.

Del análisis de la prensa anterior a la guerra civil se desprende, por tanto, que la posición de los periódicos ante la "fiesta" venía determinada por cuestiones identitarias. La exaltación de las corridas de toros por el régimen franquista contribuye a aumentar esta percepción, pero en la transición democrática el rechazo catalanista al toreo pareció disminuir cuando el diario Avui publicó por primera vez crónicas taurinas en catalán, lo que fue imitado por el diario de izquierdas en catalán Diari de Barcelona. Esta fase de incipiente catalanización de la tauromaquia cesó bruscamente cuando el resurgir del movimiento antitaurino fue aprovechado por el catalanismo independentista (que ya se había significado erradicando la publicidad del "toro de Osborne" de las carreteras catalanas) para combatir lo que consideraba un bastión de españolismo. De este modo, tanto la ley de la Generalitat que prohibía a los menores de edad asistir a las corridas (2003), como la abolición del toreo en Cataluña decretada por el parlamento autonómico (2010), se formularon en nombre de principios animalistas, lo que contrastaba con el blindaje de los "correbous", unos festejos taurinos muy populares en algunas comarcas tarraconenses donde el independentismo estaba sólidamente asentado.

Por entonces, en la prensa en castellano se producía la misma ambivalencia apuntada cuando explicábamos los casos, a comienzos de siglo, de La Vanguardia y El Diluvio. Un diario aparentemente distante del nacionalismo pero que desde 1997 publicaba una edición en catalán subvencionada, El Periódico de Catalunya, marginaba y finalmente eliminaba la información taurina de sus páginas, mientras que La Vanguardia alternaba el entusiasmo hacia el último ídolo de la Monumental, José Tomás, con la publicación de numerosas cartas contrarias a las corridas de toros. 


\section{Referencias bibliográficas}

ALMIRALL, V (1984): Articles polítics: "Diari Català" (1879-1881) (ed. J. M. Figueras), Barcelona, La Magrana-Diputació de Barcelona.

BAGÜÉS, V. (DON VENTURA) (1927): Escritores taurinos españoles del siglo XIX, Barcelona, Biblioteca de la Fiesta Brava.

BOFILL i MATES, J. (1986): Una política catalanista, i altres escrits, Barcelona, La Magrana.

BOIX, J.-ESPADA, A. (2002). Mens sana in corpore sepulto. Últimes converses amb Mariano de la Cruz. Barcelona, Edicions 62.

BOIX, S. (2011): Toros sí: una defensa razonada, Madrid, Temas de hoy.

CANTOS, J.L. (2008). La Monumental de Barcelona de Joselito el Gallo a Manolete". Almería, Círculo Rojo.

CARBALLA RIVAS, N.; GARCÍA CONZÁLEZ, A. (2014): Tratamiento periodístico de la prohibición de las corridas de toros en de la prohibición de las corridas de toros en Cataluña en la prensa nacional española desde la perspectiva del framing. Estudios sobre el Mensaje Periodístico, 20 (2), 969-985.

CASTELLÓ RIBERA, J.I. (2016): ¿La Prensa apuntilló a los toros en Cataluña?: La Vanguardia y El Periódico de Catalunya, Barcelona, Carena.

CIRICl, A. (1973): El temps barrat, Barcelona, Destino.

FABRE, J. (2017): Periodistes, malgrat tot: 1939-1966: la dificultat d'informar sota el franquisme a Barcelona: resistents, possibilistes i col/laboracionistes, Barcelona, Ayuntamiento de Barcelona.

FERRER i CODINA, A. (circa 1912): Toreros d'hivern : comedia en tres actes i en prosa. Barcelona: Impr. Ràfols.

GAZIEL (pseud. de Agustí Calvet) (1971): Història de La Vanguardia (1884-1936), París, Edicions Catalanes de París.

- (1981): Tots els camins duen a Roma: historia d'un destí: 1893-1914: memòries, Vol. I. Barcelona, Edicions 62.

GONZÁLEZ, A (1996): Bous, toros i braus: una tauromàquia catalana, Tarragona, El Mèdol.

GONZÁLEZ, A (2016): Chamaco: un heterodoxo sin causa, Barcelona, GMN.

HUERTAS, J. M. (2006): Una historia de "La Vanguardia", Barcelona, Angle. 
HUERTAS LÓPEZ, R. (1974): Historia del periodismo taurino en Barcelona (tesina inédita), Escuela Oficial de Periodismo de Barcelona.

LÓPEZ CHACÓN, R. (1946): Toros en Barcelona, Barcelona, Borrás.

LUJÁN, N. (1954): Historia del toreo, Barcelona, Destino.

- (1994): El túnel dels anys 40: memòria personal, Barcelona, La Campana.

MAÑÉ FLAQUER, J. (1856): Colección de artículos, Barcelona, Imprenta de Antonio Brusi.

MARCH, P. (2011): Crónicas para un adiós. O no (2007-2011), Barcelona, Ediciones Bellaterra.

MARTHIN GUIX, E. (1902): Corridas de toros y novillos: reglamentación taurina de Barcelona, términos taurómacos y suertes admitidas, legislación de espectáculos públicos, Barcelona, Antonio López.

MUNTANÉ, Ramon (1899): Un Torero d'hivern: corrida en un acte y en prosa, Barcelona, Impr. P. Ortega.

OLIVER, M. dels Sants (1906): Entre dos Españas, Barcelona, Gustavo Gili.

PIZARROSO QUINTERO, A. (1994). Notas para una historia del periodismo y de las publicaciones taurinas en Cataluña, Gazeta (1), pp. 303-304, 1994.

PLA, J. (1973): Obra completa. Francesc Cambó (Materials per a una història), Barcelona, 1973.

PRAT DE LA RIBA, E. (1999): La nacionalitat catalana, Barcelona, Columna-Proa.

RIEROLA, F. (1955): Dietari, Barcelona, Selecta.

RUSIÑOL, S. (2014): El català de la Manxa (epílogo de Margarida Casacuberta), Barcelona, L'Avenç.

SANTAINÉS CIRÉS, A. (1986): Domingo Ortega: ochenta años de vida y toros, Madrid, Espasa-Calpe.

SOBREQUÉS i CALLICÓ, J. (1993): Història del Futbol Club Barcelona: el Barça: un club, una ciutat, un país. (6 vols.), Barcelona, Labor.

SOLÉ i SABATÉ, J.M. (1998): El Barça en la posguerra, Barcelona, Barcanova.

- (2006): El Barça en Guerra: (1936-1939), Barcelona, Angle.

TORRENT, J.; TASIS, R. (1966): Història de la premsa catalana (2 volúmenes), Barcelona, Bruguera. 
UNO AL SESGO (pseud. de Tomás Orts Ramos) (1926): A los cuarenta y tantos años de ver toros, Barcelona, Lux.

VELA JIMÉNEZ, M (1945) iJee...Toro!, Barcelona, Luis de Caralt.

VOLTES BOU, P. (2004): Furia y farsa del siglo XX, Barcelona, Flor del viento. 